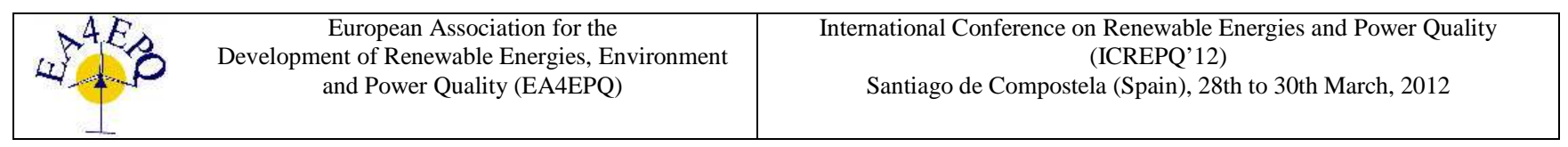

\title{
A Novel Scheme to Protect Distribution Networks in Presence of Inverter-Based Distributed Generation
}

\author{
E. Ebrahimi ${ }^{1}$, G. B. Gharehpetian ${ }^{1}$ and J. Milimonfared ${ }^{1}$ \\ 1 Electrical Engineering Department \\ Amirkabir University of Technology \\ Tehran, Iran \\ Phone/Fax number:+982164543504, e-mail: esi_ebrahimi@aut.ac.ir
}

\begin{abstract}
One of the most important challenges of distributed generation (DG) development in distribution systems is their protection. It is necessary to have a scheme for keeping the protection settings unchanged. In this paper, adverse impacts of the inverter based distributed generation (IBDG) are evaluated, and an algorithm is proposed to limit the fault current, feed, which is generated by IBDGs. This algorithm is only implemented on the inverter controller and other elements are not used in fault current limitation. The simulation results are provided to verify the proposed control scheme.
\end{abstract}

\section{Key words}

Fault current limiting, Voltage source inverter, Protection coordination, Distributed generation

\section{Introduction}

DG affects the operation of existing distribution networks protection by injecting fault currents, which were not considered when protections were originally designed. For this problem, some literatures have been proposed different protection methods, for example adaptive protection is used in [1-2]. Some DGs are used periodically, so their location and capacity will be different during the time. Therefore, the use of adaptive protection in such cases is impossible. Other solutions use advanced protection, such as the use of wavelet transform [3]. These methods require measurement instruments with high speed sampling and use complex mathematical algorithms. Therefore, their utilization is expensive and needs high skills. Some literatures have been proposed fault current limiters [4-5]. In these methods, additional power electronic switches and fault current limiting impedance are required. When a fault occurs, the power electronic switches locate impedance in fault current path and limit it. According to the mentioned content, these methods are expensive due to the use of semiconductor switches. On the other hand, due to the periodic use of a
DG, specifying the optimal location and impedance for fault current limiter fails [6].

This paper aims to address the adverse impacts of the inverter based DGs on distribution system protection, and propose a scheme to solve them. Therefore, the purpose of this paper is to develop a novel approach to control the inverter for limiting fault current.

\section{Effects of DG on Distribution Networks Protection}

In this part, some basic information about the protection of typical distribution networks is provided. Fig 1 illustrates an example of a typical radial distribution feeder with IBDGs. According to the location of the IBDG and fault, the following problem is examined.

\section{A. Fuse Coordination}

Suppose there is no IBDG installed, and fault 2 has been happened. The recloser in fast mode should operate first to discriminate for temporary fault. If fault 2 still exists, fuse 2 will blow up and cause a permanent electricity interruption. At this state, if fuse 2 does not operate, the recloser should operate in slow mode as the backup protection. To keep the coordination between the recloser and the fuse, the current passing through these devices should be stood between the minimum and maximum current illustrated in Fig. 2. The abbreviations TC and MM for the fuse identify total clearing and minimum melting characteristics, respectively while the abbreviations $\mathrm{S}$ and $\mathrm{F}$ for the recloser denote slow and fast operation modes, respectively. Now, the IBDG2 is connected to the network. In this case, the fault currents passing through the fuse and recloser are unequal. It is obvious that the fault current flowing through the fuse is higher than the fault current flowing through the recloser. This phenomenon causes miss-coordination between the 


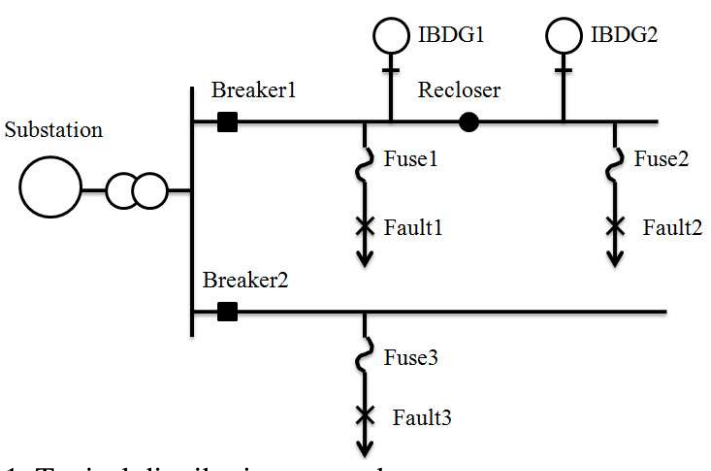

Fig. 1. Typical distribution network

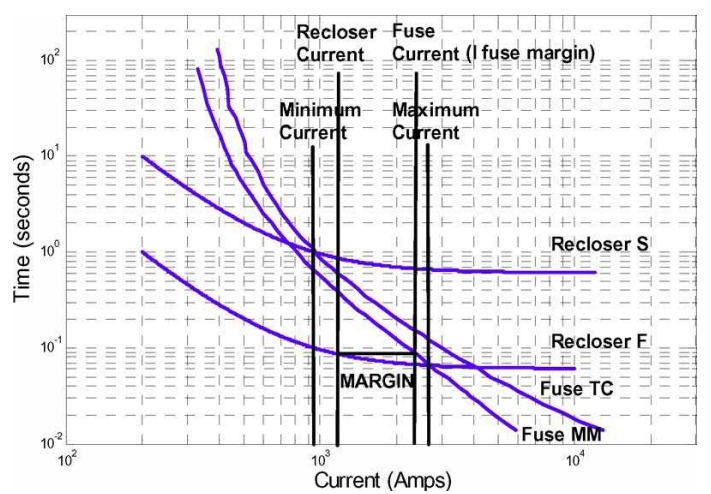

Fig. 2. Typical coordination of breaker, recloser, and fuse.

recloser and the fuse. Consequently, the fuse may operate before the recloser and a temporary fault converts to a permanent fault. To solve the aforementioned problem, a margin for the fault current should be defined. The fault current seen by fuse MM, which has the same operating time as the recloser in fast mode, is first computed and is denoted by $I_{\text {fuse }, m}$. From Fig. 3, the relation of the fault current from the utility substation and the margin or maximum fault current from IBDG can be written as [7]

$I_{\text {fuse }, m}=I_{\text {sub }}+I_{m}$

where

$I_{\text {sub }} \quad$ fault current from utility substation;

$I_{m} \quad$ margin for IBDG fault current;

$I_{\text {fuse }, m}$ current seen by fuse MM with $I_{m}$ from IBDG.

To ensure that recloserF will operate faster than fuse MM, the fault current from IBDG mast be slower than $I_{m}$, which can be expressed by the following equation:

$I_{I B D G}\left\langle I_{m}\right.$

where $I_{I B D G}$ is the fault current from IBDG.

From (1) and (2), the IBDG fault current can be calculated as shown in (3), this relation will be used later to find the threshold of the miss-coordination for the maximum acceptable fault current of IBDG.

$I_{I B D G}\left\langle I_{\text {fuse }, m}-I_{\text {sub }}\right.$

\section{Model of Inverter-based Distributed Generation}

In this paper, the treatment of DGs is investigated in fault condition and since the time constant of DGs like fuel cell and photovoltaic is considerable in comparison to fault

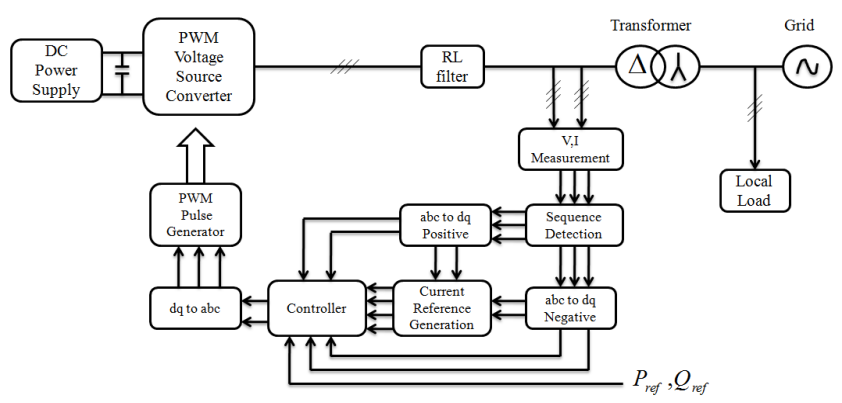

Fig. 3. Connection of IBDG to distribution system and propose algorithm

duration, the dc input of VSC is assumed constant [8]. Fig. 3, shows the assumed connection of IBDG to the distribution system where a voltage source $\left(v_{-} a b c\right)$ tracks the output of the inverter and is connected to the network bus bar via a coupling inductance $L$ and a series resistance $R$ per phase as a filter. The instantaneous power theory [9] is applied for the inverter controller designation. In this method, the amount of three-phase voltage and current measured values are converted to dq0 [10] values. Because of this transformation, instantaneous values are converted to constant ones. Consequently, the linear proportional-integral (PI) controllers can be used easily. To eliminate ripple from the real power injected into the grid by the inverter, the output current in unbalanced system could be controlled. To reach this aim, a controller is inserted on positive and negative phase sequence current components. According to linear system theory, it is possible to control these current components by the corresponding voltage components generated by the inverter. The reference currents $I_{r e f} d q, I_{r e f_{-} d q}$ can be defined via active and reactive powers. The positive sequence control variable is

$$
\begin{aligned}
V \_d q= & V_{\text {Load }}-d q+\text { PI }\left[\text { Iref_d } d q-I_{-} d q\right] \\
& +P I\left\{\begin{array}{c}
-\omega L\left[\text { Iref_ } q-I_{-} q\right] \\
\omega L\left[\text { Iref_d } d-I_{-} d\right]
\end{array}\right\}
\end{aligned}
$$

where operator PI denotes the usage of a PI transfer function $\left(K_{p}+K_{i} / s\right)$ on the error signal e. Equivalently, the negative phase sequence control variable is

$$
\begin{aligned}
V^{n}{ }_{-} d q= & V_{\text {Load }}^{n} d q+P I^{n}\left[I^{n} \text { ref_dq-I } I_{-}^{n} d q\right] \\
& +P I^{n}\left\{\begin{array}{c}
\omega L\left[I^{n} r e f \_q-I^{n} \_q\right] \\
-\omega L\left[I^{n} \text { ref_d } d-I^{n} \_d\right]
\end{array}\right\}
\end{aligned}
$$

where $P I^{n}$ denotes the transfer function for the negative phase sequence and may have various gains comparing to the $P I$ transfer function for the positive phase sequence.

\section{Proposing Control Strategy of IBDG for Limiting Fault Current}

Using positive and negative sequence components, the apparent power at grid terminals can be calculated in (6) and expressed in matrix form (7). $P$ and $Q$ are the constant or average active and reactive power, respectively, while $P_{2 c}, P_{2 s}, Q_{2 c}$ and $Q_{2 s}$ are the secondharmonic cosine and sine components of the active and reactive power. Asymmetrical and unbalanced operation of the three-phase system cause these harmonics to be 
appeared [11]. Current references are calculated (8) by setting active and reactive power references $\left(P_{\text {ref }}, Q_{\text {ref }}\right)$ and by eliminating the fluctuating active power injected to the grid $\left(P_{2 c}=0, P_{2 s}=0\right)$.

$$
\begin{aligned}
& S=\left(V \_d q . e^{j \omega t}+V^{n} \_d q \cdot e^{-j \omega t}\right) \\
& .\left(I_{-} d q \cdot e^{j \omega t}+I^{n}{ }_{-} d q \cdot e^{-j \omega t}\right)^{*} \\
& =\left(P+P_{2 c} \cdot \cos (2 \omega t)+P_{2 s} \cdot \sin (2 \omega t)\right) \\
& +j\left(Q+Q_{2 c} \cdot \cos (2 \omega t)+Q_{2 s} \cdot \sin (2 \omega t)\right. \\
& \left(\begin{array}{c}
P \\
P_{2 c} \\
P_{2 s} \\
Q \\
Q_{2 c} \\
Q_{2 s}
\end{array}\right)=\left(\begin{array}{ccccc}
V_{-} d & V_{-} q & V^{n}{ }_{-} d & V^{n}-q \\
V^{n} \_d & V^{n}{ }_{-q} & V_{-} d & V_{-} q \\
V^{n} \_q & -V^{n}{ }_{-} d & -V_{-} q & V_{-} d \\
V_{-} d & -V_{-} d & V^{n}{ }_{-} q & -V_{-}^{n} d \\
V^{n}-q & -V^{n}{ }_{-} d & V_{-} q & -V_{-} d \\
-V^{n}{ }_{-} d & -V^{n}{ }_{-} q & V_{-} d & V_{-}
\end{array}\right) \\
& \left(\begin{array}{c}
I_{-} d \\
I_{-} q \\
I^{n} \_d \\
I^{n} \_q
\end{array}\right)
\end{aligned}
$$

To remove the output power ripple, $P_{2 c}, P_{2 s}, Q_{2 c}$ and $Q_{2 s}$ values are considered zero.

$$
\begin{aligned}
& \left(\begin{array}{c}
\text { Iref_d } \\
\text { Iref__ } q \\
I^{n} r e f_{-} d \\
I^{n}{ }^{r} f_{-} q
\end{array}\right)=\left(\begin{array}{ccccc}
V_{-} d & V_{-} q & V^{n}{ }_{-} d & V^{n}-q \\
V^{n} \_d & V^{n}{ }_{-} q & V_{-} d & V_{-} q \\
V^{n}-q & -V^{n}{ }_{-} d & -V_{-} q & V_{-} d \\
V_{-} q & -V_{-} d & V^{n}{ }_{-} q & -V^{n}{ }_{-}
\end{array}\right)^{-1} \\
& \left(\begin{array}{c}
\text { Pref } \\
0 \\
0 \\
\text { Qref }
\end{array}\right)
\end{aligned}
$$

To make the matrix (7) invertible, the fluctuating reactive powers $\left(Q_{2 c}, Q_{2 s}\right)$ are ignored (8). Therefore, these reactive powers will be uncontrollable and exist in the network inevitably. Fig. 4 shows the block diagram of the current control algorithm, where the current is controlled to tracked the reference active and reactive power by changing the inverter terminal voltage. Current references are calculated using power references and terminal voltages via (8). The measured currents are then compares with these calculated reference values to obtain the error value which is applied in PI controllers to control the inverter. The dq control structure including cross coupling and feed-forward of the grid voltages is illustrated in Fig. 4. To accelerate the controller dynamic during voltage oscillating, the grid voltage feed-forward is used. In a balanced three phase system, active and reactive reference powers are determined based on the unity power factor. On the other hand, in (8) $P_{\text {ref }}=1 p u$ and $Q_{\text {ref }}=0$ have been considered. However, in fault condition in order to limit the fault current, reference powers should be limited. Therefore, the amount of active power injected to the network is determined from the maximum fault current calculated by (3) [12].

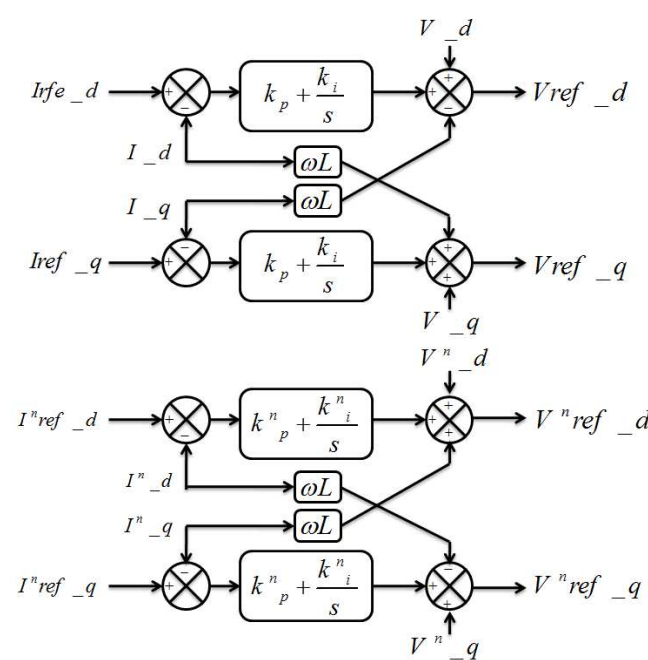

Fig. 4. Block diagram for the current control algorithm

$$
\mathrm{P}_{\text {ref_max }}=I_{\text {max }} \frac{|V|^{2}-\left|V^{n}\right|^{2}}{\left(V-V^{n}\right)}
$$

where,

$V \quad$ positive voltage magnitude;

$V^{n} \quad$ negative voltage magnitude;

$I_{\max } \quad$ maximum fault current by (3).

This method ensures that the fault current of IBDG does not exceed the threshold, and the protection coordination is still valuable.

\section{Simulation Results}

To test the performance of the proposed fault current limiting algorithm, simulations have been performed on the network shown in Fig. 1. Consider that only IBDG2 is connected and fault 2 is occurred. The IBDG is modeled as a photovoltaic array. The upward network is modeled as a three phase ideal voltage source in series with an R-L branch in each phase as the thevenin impedance. The output filter of the converter is assumed to be $0.45 \mathrm{mH}$. In this paper, the returned current from the machine loads is ignored during the short circuit condition. At first, it is assumed that IBDG is controlled with a conventional controller. Single phase fault (AG) occurs at $t=0.1 \mathrm{~s}$ as Fault2. It is shown in Fig. 5 that with conventional controller the maximum fault current exceeds $2 \mathrm{pu}$, and the active and reactive power will fluctuate considerably. Now, it is assumed that the IBDG2 is controlled using the proposed controller. It is shown in Fig. 6 that in this case, the fault current of IBDG2, will be an acceptable limiting. Also, the active and reactive power fluctuates in acceptable range due to d-axes and q-axes of current are almost smooth.

\section{Conclusion}

High penetration of distributed generation in distribution systems causes miss-coordination in the protection system. To solve this problem, researchers propose changing of protection settings, application of fault current limiters or other protection methods like adaptive protection. In the presence of inverter based distributed generators, limiting fault current can be 
implemented by inverter control. Therefore, the main aim of this paper is the proposal of a controller algorithm for limiting the fault current. The proposed algorithm not only limit the fault current but also can control the power generated by IBDG and avoids the active power fluctuations in fault condition. By using the proposed controller, there is no need to use additional elements for fault current limiting, so the proposed solution of this paper can be economical.

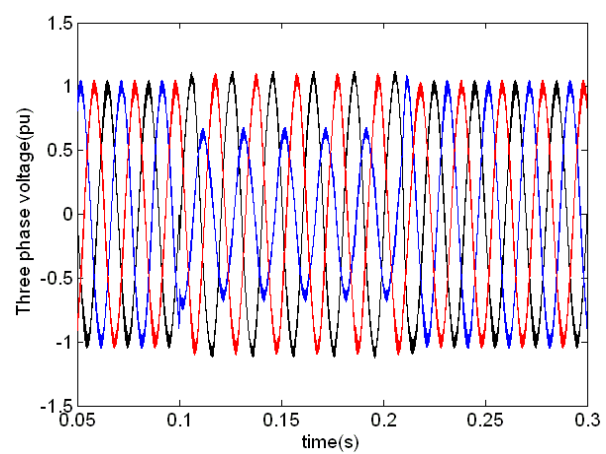

(a)

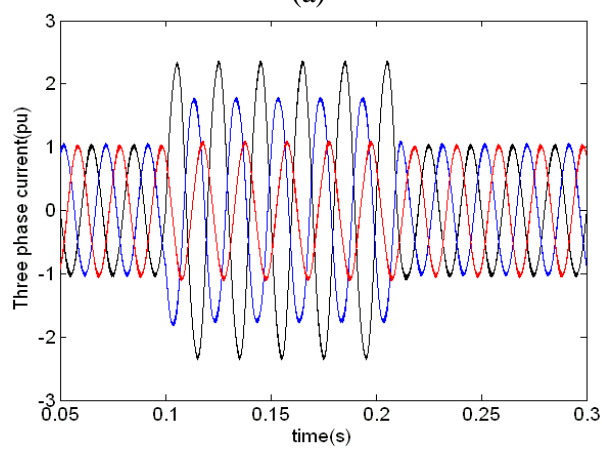

(b)

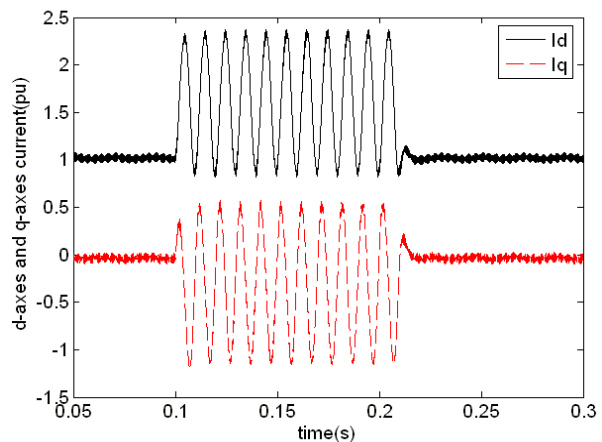

(c)

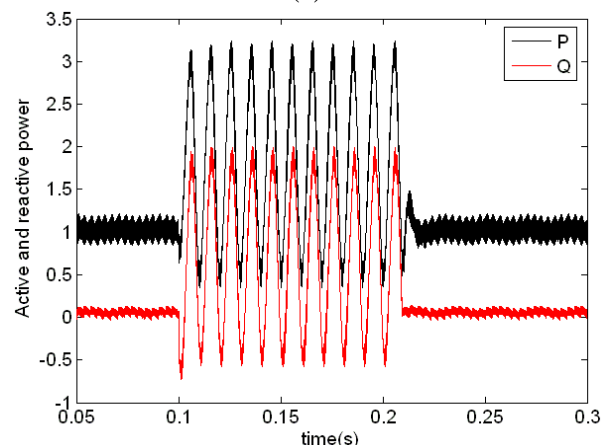

(d)

Fig. 5: Conventional controller, (a) three phase voltage, (b) three phase current, (c) dq-axes current and (d) active and reactive power

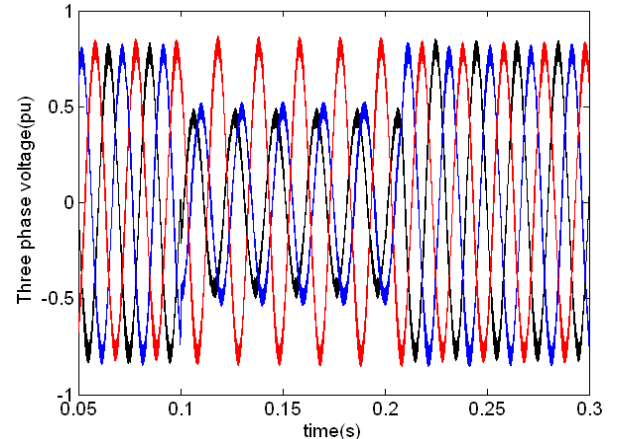

(a)

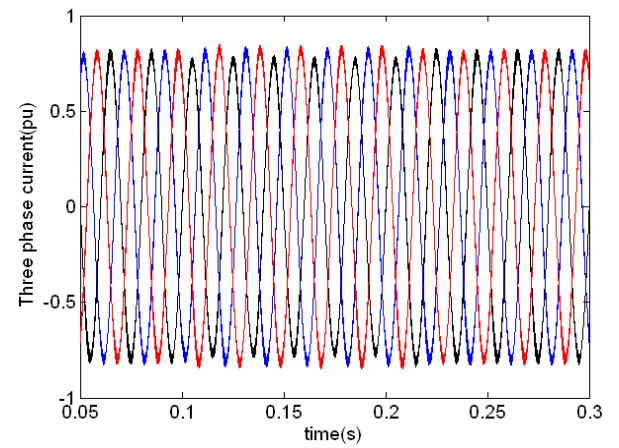

(b)

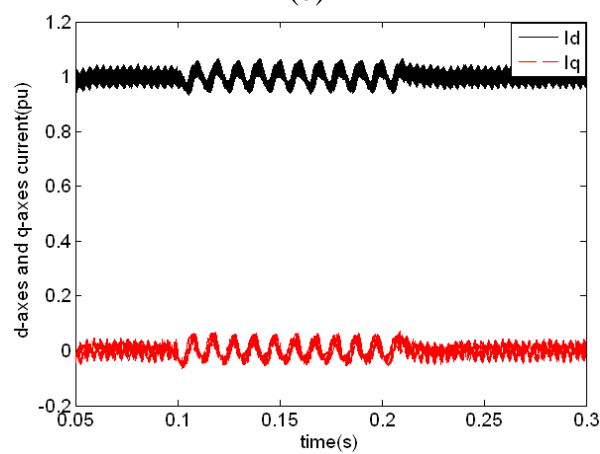

(c)

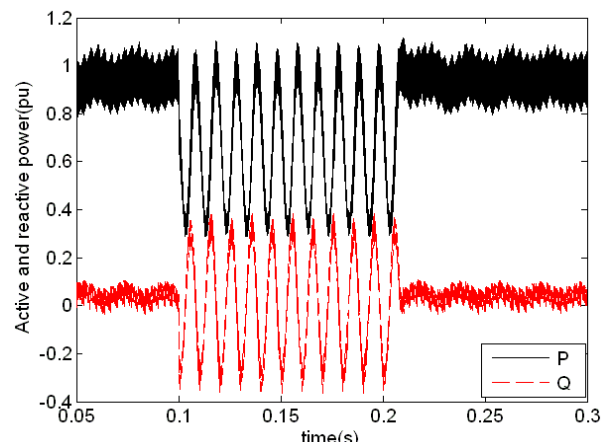

(d)

Fig. 6: Proposed controller, (a) three phase voltage, (b) three phase current, (c) dq-axes current and (d) active and reactive power

\section{Reference}

[1] S. M. Brahma, and A. A. Girgis, "Development of adaptive protection scheme for distribution systems with high penetration of distributed generation" IEEE Trans. Power Del., vol. 19, no. 1, pp. 56-63, Jan. 2004.

[2] P. Mahat, Z. Chen, B. Bak-Jensen, and C. L. Bak, "A simple adaptive overcurrent protection of distribution systems with distributed generation" unpublished.

[3] N. Perera, A. D. Rajapakse, and T. E. Buchholzer, "Isolation of faults in distribution networks with 
distributed generators" IEEE Trans. Power Del., vol. 23, no. 4, pp. 2347-2355, Oct. 2008.

[4] T. Sato, M. Yamaguchi, T. Terashima, S. Fukui, J. Ogawa, H. Shimizu, and T. Sato "Study on the effect of fault current limiter in power system with dispersed generators" IEEE Trans. Appl. Superconduct., vol. 17, no. 2, pp. 23312334, Jun. 2007.

[5] W. El-Khattam, and T. S. Sidhu, "Restoration of directional overcurrent relay coordination in distributed generation systems utilizing fault current limiter" IEEE Trans. Power Del., vol. 23, no. 2, pp. 576-585, Apr. 2008.

[6] H. R. Baghaee, M. Mirsalim, M. J. Sanjari, and G. B. Gharehpetian, "Fault current limiting in distribution systems with distributed generation units dy a new dual functional series compensator" 2nd IEEE International Power and Energy Conference (PECon), pp. 537-542, Dec, 2008.

[7] S. Chaitusaney, and A. Yokoyama, "Prevention of reliability degradation from recloser-fuse miscoordination due to distributed generation" IEEE Trans. Power Del., vol. 23, no. 4, pp. 2545-2554, Oct. 2008.

[8] N. Nimpitiwan, G. T. Heydt, R. Ayyanar, and S. Suryanarayanan, "Fault current contribution from synchronous machine and inverter based distributed generators" IEEE Trans. Power Del., vol. 22, no. 1, pp. 634-641, Jan. 2008.

[9] H. Akagi, E. H. Watanabe, and M. Aredes, "Instantaneous power theory and application to power conditioning" John Wily \& Sons, Inc., Hoboken, New jersey, ISBN. 978-0470-10761-4.

[10] C. Hochgraf, and R. H. Lasseter, "Statcom controls for operation with unbalanced voltages," IEEE Trans. Power Del., vol. 13, no. 2, pp. 538- 544, Apr. 1998.

[11] S. Alepuz, S. Busquets-Monge, J. Bordonau, J. A. Martínez-Velasco, C. A. Silva, J. Pontt, and J. Rodríguez, "Control Strategies Based on Symmetrical Components for Grid-Connected Converters Under Voltage Dips" IEEE Trans. Ind. Electron., vol. 56, no. 6, pp. 2162-2173, Jun. 2009.

[12] P. Rodriguez, A. V. Timbus, R. Teodorescu, M. Liserre, and F. Blaabjerg, "Flexible Active Power Control of Distributed Power Generation Systems During Grid Faults" IEEE Trans. Ind. Electron., vol. 54, no. 5, pp. 2583-292, Oct. 2007. 